\title{
La Universitat de Cervera: Un projecte reformista frustrat
}

\author{
The University of Cervera: A frustrated reformist Project
}

\author{
JoAquim Prats \\ joaquimprats1@gmail.com
}

Universitat de Barcelona

\begin{abstract}
Resum: La universitat de Cervera, fundada per Felip V, suposà una fita important per a Catalunya: per un costat, naixia com un projecte borbònic de futur i, per un altre, significava que les universitats catalanes històriques havien estat abolides, en virtut de la política repressora del nou monarca. El present article analitza aquella institució i el fracàs d'aquell projecte. La creació de la Universitat ha de situar-se en un context reformista de tall centralista, propi de les noves monarquies europees que van prendre com a imatge la cort i l'acció en política interna de Lluís XIV. Tanmateix, amb el pas dels anys, aquella proposta es va veure frustada.
\end{abstract}

Paraules clau: Universitat de Cervera, orígens, declivi, Catalunya, segle XVIII

Abstract: The University of Cervera, founded by Philip V, was an important milestone for Catalonia: on the one hand, it was born as a Bourbon project for the future and, on the other, it meant that historic Catalan universities had been abolished, under the policy repressive of the new monarch. This article discusses that institution and the failure of that project. The creation of the University must be situated in a reformist context of a centralist nature, typical of the new European monarchies that took as their image the court and action in domestic politics of Louis XIV. However, over the years, that proposal was thwarted.

Key words: University of Cervera, foundation, declivity, Catalonia, 18th. century

\footnotetext{
* Una part no substancial d'aquest escrit, encara que no en la seva literalitat, van ser publicat en castellà a: J. Busqueta y J. Pemán. (coord.) Les Universitats de la Corona d'Aragó, abir i avui. Estudis Històrics. Barcelona: Ed. Pòrtic. 2002 (ISBN: 84-7306-756-8)
} 
La creació de la Universitat ha de situar-se en un context reformista de tall centralista, propi de les noves monarquies europees que van prendre com a imatge la cort i l'acció en política interna del Rei Sol. S'emmarca en un primer intent de renovació dels centres universitaris, dirigit pels sectors regalistes de la Corona, molt abans de l'arribada dels impulsos reformistes de la segona meitat de segle XVIII.

La idea matriu era una aliança doctrinal, entre la Corona i l'ensenyament superior, conforme amb una concepció monàrquica centralista i autoritària llavors vigent, que pretenia, entre altres coses, solidificar el dret privatiu del rei sobre determinades regalies i racionalitzar tot el mapa social i institucional de la nova dinastia, on no hi podia mancar, encara que no resulti evident, l'àmbit universitari. ${ }^{1}$

La Universitat de Cervera va ser fundada a l'any 1717 pel rei Felip V de Borbó, aprofitant el desmantellament institucional que es va produir a Catalunya amb motiu del desenllaç de la Guerra de Successió espanyola i amb voluntat d'enfortir l'absolutisme per part de la nova dinastia

La seva creació va suposar la fusió de les set universitats que hi havia a Catalunya fins a aquell moment: Barcelona, Lleida, Girona, Vic, Solsona, Tarragona i Tortosa. En realitat, només dues universitats de les esmentades, Lleida i Barcelona, tenien una certa entitat. La resta eren centres molt petits, de dependència municipal, alguns conventuals o episcopals, que tenien pocs professors i alumnes.

Cervera, va concentrar rendes i estudiants en una universitat, única per a tot el Principat, tot exercint el monopoli dels estudis superiors (Prats 1993). Aquesta circumstància va convertir a Cervera en un dels majors centres d'ensenyament superior de la Corona, probablement el segon o tercer quant a finançament i nombre d'alumnes. Cal recordar que la necessitat de crear una gran universitat a Catalunya era una idea ja defensada per alguns arbitristes o polítics de la Catalunya des de finals del segle XviI, com Narcís Feliu de la Penya.

En aquest article explicaré les circumstàncies del seu naixement, el pla reformista que el va inspirar i el relatiu fracàs del projecte, tal com havia estat concebut pels personatges filipistes que l'impulsaren.

La història de la Universitat de Cervera ha merescut l'atenció de molts escriptors i no masses historiadors. No existien, fins fa pocs anys, recerques riguroses que expliquessin amb suficient fonament $\mathrm{i}$ base documental, què va ser $\mathrm{i}$ quins trets va tenir l'únic centre universitari català durant més d'una centúria. Cal exceptuar dos volums recopilatoris d'un important nombre de documents que actualment es troben a la Biblioteca/arxiu Universitat de Barcelona editats l'any 1910 per Manuel Rubio Borràs (Rubio Borrás 1915).

\footnotetext{
1 Els regalistes i els reformistes propugnaven -a més de processos moderats de secularització-, la implantació de fortes mesures que evitessin la corrupció en les universitats, la racionalització del nombre de centres i el control sobre els continguts de l'ensenyament al servei del que consideraven que eren les noves necessitats econòmiques i polítiques del país.
} 
Vaig tenir la fortuna d'ampliar, significativament, les fonts documentals al Archivo Histórico Nacional (AHN), on vaig «descobrir» més de 35 lligalls sense catalogar. Aquests contenien documentació, ben organitzada, variada i rica, que m’han permès, juntament amb la documentació trobada a d'altres arxius (Simancas, ACA, Osca, Tolosa ets.), poder treballar amb suficient fonament, la història de la universitat.

Aquest treball no pretén fer una anàlisi de l'enorme quantitat de literatura publicada, sobre aquesta institució, que, amb anterioritat, ja vaig publicar a la revista Manuscrits: «Historiografia y publicismo sobre la Universidad de Cervera. Entre el mito y el Sanbenito» (Prats 1987a). Resumint els diferents enfocs publicats sobre la història de la Universitat, es poden considerar dues tendències cabdals, a més de nombrosos escrits de caràcter anecdòtic o erudit. Les dues interpretacions més destacables són (Prats 1998):

La primera, amb molts matisos entre els diversos autors, es basa en l'acusació de «botiflerisme» del centre, sobretot per l'estigma de la seva fundació borbònica i el seu final, tan lligat a l'absolutisme de Ferran VII (els darrers anys va ser procarlina). Els autors que defensen aquesta tesi pertanyen a la historiografia romàntica del segle XIX i s' identifiquem amb criteris nacionalistes o prenacionalistes.

La segona, també amb matisos, és la que reivindica la qualitat, el seu catalanisme i la seva ortodòxia catòlica elaborada per escriptors, majoritàriament eclesiàstics, com Federic Clascar (Clascar 1918); el jesuïtes Ignasi Casanovas (Casanovas 1934) i Miquel Batllori, entre d' altres, seguint les línies que va marcar el bisbe Torres i Bages en el seu llibre: La tradició catalana. (Torras i Bages: 1882). En general, critiquen la Universitat de Barcelona restituïda, a la qual qualifiquen de liberal, heterodoxa i poc defensora de «lo català» i de la llengua catalana.

Hi ha una síntesi, de tots dos plantejaments, de caire nacionalista, que salva a la Universitat, com a important focus cultural, per la docència de determinats acadèmics (Josep Finestres, Tomàs Cerdà, Llucià Gallissà i Costa, Josep Coll Dorca, Llàtzer de Dou, entre altres), però, al mateix temps, condemna el seu origen com a conseqüència del desenllaç de la Guerra de Successió. Aquesta posició, que ha estat hegemònica d'una determinada historiografia, fou defensada per l'historiador Ferran Soldevila, en el seu llibre Barcelona sense Universitat publicat als anys trenta del segle passat. (Soldevila 1938)

\section{El perquè de la creació d'una Universitat}

La Universitat es creà per l'acció i l'obstinació de determinats personatges de l'administració de la Corona aliats amb la Companyia de Jesús. Aquest grup, amb posicions regalistes, va aprofitar el context de les reformes dels decrets de la Nova Planta, per a imposar el pla d'un nou centre docent d'ensenyament superior. 
Encara que els artífexs polítics de la Nova Planta, en el seu vessant més polític, no van veure, de bon començament, amb interès aquest projecte aliè, donat que el tema universitari no es veia com a prioritari, al llarg del segle XVIII l'interès variaria amb els governs il lustrats.

Els promotors de la Universitat van actuar amb l'autorització del rei Felip V però amb poca sintonia, en relació a les noves autoritats borbòniques de Catalunya. A més, tenien l'oposició d'alguns Ordes religiosos, sobretot dels dominics, i també dels bisbats. El poder de les ciutats (Barcelona, Lleida, Vic i Girona) titulars de les universitats ja no comptava, atès que s'havia desfet l'estructura del poder municipal anterior (Prats 1993).

En el cas de Cervera, es va procurar plasmar les idees de canvi que defensaven els sectors regalistes, prereformistes, segons la qualificació de Domínguez Ortíz. (Domínguez Ortiz: 1976). Recordem el que critica i quin model d'Universitat proposa Melchor de Macanaz en el seu Testamento de España (Macanaz: 2001).

Aquestes idees es centraven en una tendència de relativa secularització de les universitats, de reforma dels ensenyaments, d' un control més directe de la Corona, especialment pel que fa al finançament i el govern intern.

Els precedents eren clars i protagonitzats pels mateixos personatges que estaven darrere de la creació de Cervera: l'intent de reforma de la Universitat de Saragossa l'any 1714, o el de la Universitat de Sevilla i Osuna, o el de Salamanca (Polo Rodriguez 1994, AA. DD. 1983; Aguilar Piñal 1969) pretenien un control efectiu de la Corona sobre la institució universitària. Tots aquests propòsits varen fracassar per la incapacitat de la Corona d'entrar en el si de cadascuna d'elles. A Catalunya fou possible ja que la Corona va tenir les mans lliures per actuar i modificar la major part d'institucions que, després de la guerra, varen quedar inermes per a defensar-se.

No hi ha dubte que el disseny de la Universitat de Cervera va en aquesta mateixa línia. Va suposar una notable novetat en el panorama de l'ensenyament superior, avançant-se quaranta anys a les reformes propugnades per Pérez Bayer, Campomanes i Jovellanos. Una altra cosa va ser el resultat real de l'experiència.

La fundació d'aquesta Universitat es va realitzar amb una gran complicitat per part de la Companyia de Jesús. La seva influència mitjançant els confessors jesuïtes del nou monarca fou notòria. ${ }^{2} \mathrm{~A}$ Catalunya, els jesuïtes reivindicaven, des de dècades anteriors, tenir un major protagonisme a les universitats, després dels fracassos i dificultats experimentats a la Universitat de Barcelona, controlada pels professors tomistes.

\footnotetext{
2 Un dels confessors que va influir amb més eficàcia per a la consolidació de la Universitat a Cervera, en el moment en què el suprem Consell de Castella va sol licitar al Rei que reconsiderés el seguir amb el projecte, va anar Guillermo Clarke, jesuita d'origen británic. Aquest personatge va elaborar, en 1728, un informe per a reformar els Col legis Majors (Arxiu General de Simancas Gr. i Jus. leg. 942 sense fol. informe 4 maig 1728). La seva proposta no va prosperar. La reforma d'aquestes institucions no es va fer fins a temps de Carles III.
} 
Els promotors, especialment el primer protector Luis Curiel i Tejada, partien de dues premisses (Prats 1993):

- En primer lloc, per l'existència de massa universitats en un "país reduït en extensió», amb pocs estudiants, on els professors cobraven molt poc.

- En segon lloc, com assenyalà igualment Luis Curiel: «son demasiados los que se dedican a 'estudios literarios', más de los que son necesarios para el estado eclesiástico, para abogados, jueces y médicos, con perjuicio conocido de la agricultura, el comercio y artes mecánicas». ${ }^{3}$

El projecte implicava les següents línies de reforma, que van estar presents durant bona part del segle en la política de la Corona, amb resultats molt desiguals:

1. Control de la Corona sobre els nomenaments de càrrecs i catedràtics.

2. Enfortiment dels nous corrents del pensament en els plans d'estudi. Domini total del regalisme en els estudis de dret i sobretot de cànons (Llaquet Entrambasaguas: 2002).

3. Acabar amb les freqüents lluites entre les anomenades «sectes suarista i tomista».

4. Intentar el màxim nivell d'autonomia respecte dels poders fàctics de les universitats tradicionals. A Catalunya: corporacions municipals, bisbats, ordres religioses.

\section{Sistema de govern}

Un element nou, per a l'època, va ser el seu sistema de govern. Per primera vegada el poder polític, la Corona, controlava directa i, quotidianament, una institució universitària enfront de la tradicional estructura corporativa dels centres superiors. Així, la Universitat de Cervera es va crear com un centre depenent del Suprem Consell de Castella, en el qual ni els bisbes locals, ni els capítols catedralicis, ni els Ordes religiosos, ni els ajuntaments tingueren directament cap poder institucional significatiu.

Tres eren els puntals previstos per al govern de la Universitat: el Ministre Protector, el Cancelario (Canceller) i el Claustre de professors (Prats 1993; Rubio Borrás 1915).

3 Arxiu Universitari de Cervera. (UB). Caixa 310, doc. 2000. 


\title{
Joaquim Prats. La Universitat de Cervera: Un projecte reformista frustrat
}

Tot el poder quedava a mans d'una sola persona: el Cancelario, nomenat. Però la Corona volia reservar-se l'absolut control del nou centre. Per a això, es va nomenar un nou càrrec, el «Ministro Protector», antecedent dels Directors d'Universitat de l'època de Carles III. Es tractava de designar un membre del Consell de Castella, al qual se li encomanava la tasca, no sols de supervisió, sinó de resolutor de les principals decisions. El nomenament del primer protector, Luis Curiel, expressà amb claredat aquestes característiques:

\begin{abstract}
Siendo por conveniente que para el más puntual cumplimentado de lo referido (llevar a cabo el proyecto de creación y consolida $\neg$ ción de la Universidad) halla un ministro de mi Consejo que sea Protector «con la misión» de dar todas las órdenes y providencias que os parecieren convenientes (...) así mismo os damos facultad para que podáis conocer de todos los pleitos, causas y negocios (...) llamando y oyendo las partes interesadas, haciéndoles justicia (...); para cuyo efecto mando a cualesquiera Tribunales y justicias ante quienes estuvieran pendientes (los pleitos de la Universidad con otros) os los remitan en el estado en que se hallaran «las apelaciones se harán si las hubiere, ante el Consejo de Castilla» y no ante otro Juez ni Tribunal alguno, porque los demás Consejos, Cancillerías, Audiencias, Tribunales, Justicias ordinarias y otros ministros los inhibo (...) y les mando no se entrometan en él con ningún pretexto; porque sólo Vos (Luis Curiel) en primera instancia, habéis de conocer privativamente de todo ello. ${ }^{4}$
\end{abstract}

La figura del Ministre Protector va néixer doncs en funció de la necessitat de garantir l'autonomia política per tal de dur a terme el projecte. Aquest càrrec atípic va provocar disfuncions i confusió en els canals i mecanismes de decisió. Els problemes van ser freqüents, no sols en el si de la cúpula de poder de la Corona, sinó també entre aquesta i la pròpia Universitat.

El govern directe de la Universitat va ser atorgat al Cancelario (canceller), única autoritat a l'organigrama en suprimir-se, l'any 1718, el càrrec de rector i acabar amb la bicefàlia tradicional de les universitats de l'època (canceller i rector). El nomenament del Cancelario el feia directament el Rei sense cap consulta oficial prèvia.

Els «Cancelarios» van ser catalans des de la fundació de la Universitat fins a 1752 i de 1803 fins a 1832, data en la qual va desaparèixer aquesta figura i es va crear, de nou, la de Rector. Les magistratures unipersonals («Vicecancelario», bidell $\mathrm{i}$ altres) del govern universitari eren cobertes per designació reial, altres per designació del Cancelario i uns altres per elecció del claustre.

El Cancelario exercia tant la jurisdicció eclesiàstica ${ }^{5}$ com la jurisdicció civil entre els membres acadèmics, estudiants i professors, així com dels empleats i servidors del Centre (Prats 1994). Els

\footnotetext{
4Nomenament com Protector de la Universitat a Luis Curiel (Rubio Borràs 1915: 156-161).

5 La Butlla «Imperscrutabilis» va ser promulgada pel Papa el 4 de desembre de 1730. En aquesta Butlla, a més del reconeixement de la Universitat, s'atorgava al Cancelario: «Jurisdiccio Ordinaria, Eclesiastica, Civilis et Criminalis, privativa ad quosqumque Judices, vi cuius nulla persona Academica potest conveniri nisi coram Scholastico Cervariensi (...)», aixi com la «Jurisdictio Conservatoria Eclesiastica cuius virtute quilibet Academicus trahit ad Tribunal Conservatoris reum non Academicum». La Butlla es troba a la secció de Reserva del Arxiu de la Universitat de Barcelona
} 
conflictes entre les diferents jurisdiccions: acadèmica, militar, civil i eclesiàstica, van ser freqüents durant tot el segle XviII.

El principal òrgan col legiat de la Universitat va ser el claustre, configurat com a «gremi acadèmic». La corporació claustral, jerarquitzada i dividida en Claustre de Diputats i Claustre Ple, tenia entitat jurídica pròpia. El claustre de Cervera va heretar totes les característiques tradicionals de les corporacions acadèmiques d'aquella època: entre tots es lluitava, sobretot, per a la defensa dels seus privilegis ( Prats 1993; Rubio Borrás 1915).

\section{Com es finançava la Universitat?}

Cervera era una Universitat, jurídicament, resultant del trasllat i agrupament de les preexistents a Catalunya. Les seves rendes eren la suma de les que tenien les universitats catalanes fins al moment de la seva desaparició el 1717. El gruix de les partides aportades provenien de les ciutats de Barcelona («dret de portes») i Lleida (Lliura del vi i altres conceptes). Es va eximir de contribuir als Ordes religiosos, però no a les ciutats i als bisbats (Prats: 1993). En diverses ocasions la Corona va aportar diners suplementaris o alguns censos o tributs ( Vara del Aguacil de Carmona i altres conceptes») en els moments en el que les finances universitàries varen entrar en dèficit.

En conjunt, la Universitat de Cervera es va situar en els primers llocs de la Corona per la quantia del seu pressupost. Els ingressos anuals de la Universitat, a partir de 1734, oscil laven entre les quinze i vint mil lliures catalanes. A aquesta xifra, que cobria el pressupost ordinari, cal afegir-li unes tres mil lliures anuals que pagava la ciutat de Cervera, destinades a la construcció de l'edifici, pagament que havia de fer-se per subrogació del cadastre i per alguna altra exempció fiscal (Mora Castellà 1997).

\section{El fracàs de l'experiència}

La nova Universitat, concebuda pels seus promotors com un pas important per a la renovació dels estudis universitaris no va arribar a realitzar-se tal com s'esperava. El seu propi procés de creació va ser tan conflictiu que va marcar una deriva mediocre $i$ va ser finalment oblidada pels poders polítics de la Monarquia tant en la seva administració central, com en la territorial.

Des de la defunció del primer protector Luis Curiel i Tejada, l'any 1724, el projecte va deixar de comptar amb un valedor qualificat que tingués clar el que era una reforma universitària com la que va generar la fundació del centre. Els següents protectors, van ser més càrrecs de control polític i de relativa protecció enfront de les envestides que rebia la Universitat d'altres instàncies de la Corona, sobretot de les que governaven directament a Catalunya. 


\title{
5. E1 llarg i conflictiu procés de creació (1717-34)
}

La reforma universitària es va forjar al marge i en relativa oposició als organismes de caràcter polític que van dissenyar i van administrar la Nova Planta: la Real Junta Suprema de Justícia y Gobierno de Cataluña, dels primers Capitans Generals, i de l'Intendent General. Posteriorment, la Real Audiència tampoc la va veure amb massa simpatia. No va tenir, des de l'any 1725 fins a 1730, el suport incondicional del Suprem Consell de Castella, organisme del qual depenia la nova universitat.

L’oposició més frontal va provenir de l'Església. Si no era reconeguda pel papat, la Universitat es quedava tan sols amb el títol de Real Universidad però no rebia el títol de Pontifícia, fet pel qual els títols sols tenien valor dins de la Corona Hispànica, però no validesa universal. Son moltes les representacions de bisbats en contra de la creació de la nova Universitat. El capítol catedralici del bisbat de Lleida va reclamar varies vegades la recuperació de la Universitat a la seva diòcesi. Un exemple, dels escrits i reclamacions que es poden trobar és aquesta carta, dirigida al papa, on es posava de manifest:

\begin{abstract}
Sei un grandisimo pregiudizio de cittadini ilerdensis» y la traslación de rentas «sarebbe direttamente contraria alla mente e volontá delli fondatori tanto piu per esser la cittá de Cervera situata in diocesi diversa». Calificando el traslado dela Maestre escolanía como un atentado y suplican «no voler concedere grazia alguna concernente (...) alla Universitá (...) senza sentire le raggioni di Monsignore Vescovo (era el Obispo) e del Capítulo» (donat que l' intencio inicial de Felip rey) (...) «sempre e stata che dalla provisionalle traslazione della Universitá de studis di Lérida alla citta di Cervera non debba resultare prejudizio alcuno alla chiesa Cattedrale, e che non debba vulnerarsi li privilegi. ${ }^{6}$
\end{abstract}

Des de la publicació l'11 de maig de 1717 del Real decreto de Erección, ${ }^{7}$ fins a la promulgació de la Butlla per la qual s'atorgava al nou centre la categoria de Pontifícia (Butlla Imperscrutabilis) (Prats 2016) $\mathrm{i}$ les butlles que atorgaven les rendes episcopals, va passar un període de disset anys.

Finalment, després d'una llarga negociació diplomàtica, en la qual van participar el cardenal Bentivoglio (cardenal prodatari) i el cardenal Belluga, es va reconèixer la Universitat, coincidint amb la investidura d'un nou papa, Climent XII (1730). L'anterior, Benet XIII, fou enemic de la corona hispana i contrari a la creació de la Universitat de Cervera.

Els bisbes catalans sempre es mostraren poc predisposats a traslladar rendes $\mathrm{i}$ fins $\mathrm{i}$ tot a reconèixer de facto el nou centre. De fet, malgrat tenir el monopoli dels estudis, es seguien fent classes al seminari tridentí i a alguns convents. Després enviaven als alumnes a graduar-se a la universitat d'Osca o a la de Palma. Algunes dades que avalen les dificultats d'aquest primer període (17171734) són:

6 Arxiu Universitat de Cervera. (UB). Caixa 50, doc. no 5095

7 El Real Decreto de Erección... de 11 de mayo de 1717. ARCHIVO HISTÓRICO NACIONAL (AHN) Consejos Suprimidos (C.S.) Leg. 50842 y 50853.

SCRIPTA, Revista internacional de literatura i cultura medieval i moderna, núm. 15 / juny 2020 / pp. 241-254 
- En els tres anys anteriors a la seva creació (1717), la Junta Suprema de Govern de Catalunya va demanar revisar la decisió, proposant la creació de dues universitats.

- El Suprem Consell de Castella, a la mort Luis Curiel (1724), va demanar al Rei detenir el procés de creació i tornar a la situació anterior restituint Lleida i Barcelona. L'ofensiva d'aquest sector de «consejeros ultramontanos» de la Cort gairebé va aconseguir suspendre el projecte. Aquí van jugar molt fort els jesuïtes amb el suport del confessor reial.

- L'Assumpte Meca. Al 1728 la catedral de Lleida va aconseguir nomenar un canceller (el mestrescola de la catedral) contra l'opinió del protector i de la universitat $i$ aquest va intentar fer tornar la universitat a Lleida. Durant aquest període el rei no va anomenar Cancelario a l'espera de la negociació amb el papat que es va resoldre en $1731 \mathrm{amb}$ la butlla Imperscrutabilis i en $1734 \mathrm{amb}$ les butlles de translació de rendes dels bisbats a la universitat (Prats: 2016).

L'ambiciós projecte dels promotors del nou estudi va xocar, des del primer moment, amb una realitat hostil, per dos motius:

En primer lloc, amb la impossibilitat d'aconseguir el finançament necessari (els bisbats es van negar a pagar la seva part si no hi havia una butlla papal). Després varen ser molt morosos, com es pot deduir del gran nombre de litigis a lo llarg del segle. La Corona va haver d'ajudar, amb finançament, més d'una vegada, a l'entitat. En segon lloc, va ser impossible paralitzar els estudis superiors en centres religiosos i seminaris (recordem que la Universitat tenia el monopoli dels estudis superiors al Principat). Les accions de la Universitat denunciant «el contrabando de los estudios», es perllongaren en el decurs de tota la centúria. (Prats 1993).

La manca de col laboració de l'Audiència i del mateix Capità General amb aquests dos temes, es va veure agreujada per les discrepàncies amb el projecte en el propi Consell de Castella. Així ho manifestava el Protector:

\footnotetext{
Eran muchas las contradicciones que por todas partes se oponen a los progresos de la Universidad (...)», diu Curiel, «todas las autoridades del Principado son contrarias (...) e incluso dentro del Consejo de Castilla existen «poderosos enemigos (...) que parece que buscan pretextos para entorpecer». ${ }^{8}$ En un altre escrit diu: «En Cataluña no hay persona de mérito que no esté opuesto a ello (la aplicación del Decreto de Erección) y acá (la Corte) no faltan detractores.
}

8 Arxiu Universitari de Cervera. (UB) Caixa 130 doc. 1173.3

9 Arxiu Universitari de Cervera. (UB) Caixa 1 doc. 4743.4. 


\section{Final de l'experiència cerverina}

Des del punt de vista del sistema de govern, una de les causes d'inviabilitat de l'experiència va ser el singular model de govern que s'havia dissenyat: un Protector a Madrid i un Cancelario a Cervera. Quan el centre va anar aconseguint un grau d'estabilitat, les relacions entre els dos càrrecs esdevingueren conflictives i incompatibles.

Els conflictes més importants es van produir amb l'arribada de Manuel Alós a la cancelleria. El xoc freqüent i el continu desacord del Cancelario Alós amb els dos protectors amb els quals va coincidir va ser evident en moltes ocasions. Al 1742, després de la mort Bernardo Santos, el va succeir Josep Ventura Güell.

Ventura Güell va intentar controlar els més petits detalls del funcionament universitari. Alós va desobeir reiteradament, a l'empar de la protecció que trobava en el confessor real, el pare jesuita Francisco Rávago i en els seus germans que ostentaven importants càrrecs polítics i militars. El desenllaç d'aquesta rivalitat va ser la dimissió de Ventura Güell, el qual, tot sovint, es sentia desautoritzat pel Rei. Després de la renúncia d'aquest no es va tornar a cobrir el càrrec. El model bicèfal, un a la cort i l'altre a la Universitat, no havia funcionat. (Prats 1993)

El conflicte es va produir també amb altres institucions pocs anys després. El punt de major crisi es va produir el 1748. Els fets es van centrar a resoldre qui havia de jutjar i sancionar a un estudiant que s'havia burlat d'uns soldats en trànsit. El desenllaç va ser l'ordre expulsió del país cap a l'exili del Cancelario Manuel Alós. Aquest fet va suposar un cop dur per a la institució, atès que es va veure sense el seu cap per ordre expressa del Rei, i aconsellat pel Marqués de la Ensenada.

El període que va fins a 1771, pot ser considerat com a una etapa, en la qual la forma de govern del centre era encara singular, pel que fa a la resta de les institucions universitàries de l'època. La Corona, després dels fets de 1742 i 1748, va deixar d'interessar-se per Cervera i no va prestar massa atenció al model creat. La Universitat es va deixar de banda, tal i com palesen diversos testimonis.

Junt a aquest oblit de la Corona, la Universitat va patir litigis freqüents pel que es qualificava de: «contrabando de titulos». Eren varies les institucions que feien classes a Barcelona i enviaven a examinar-se als seus estudiants a universitats fora de Catalunya. La ciutat reivindicava freqüentment la tornada dels estudis a la capital catalana, fet que també va influir a «consejeros i ministros de su Majestat» (Prats: 187b) a l'hora de definir el tractament tan displicent vers la Universitat. De fet, al llarg del segle, trobem nombroses reclamacions, ben documentades, sense la presència, en el govern del centre, de cap dels inicials defensors del projecte. Ja en el tron Ferran VI, l'Ajuntament de Barcelona va elevar una representació al monarca en la qual es propugnava la fi de la Universitat de Cervera i l'establiment d'aquesta a Barcelona. Pel 1755, apareixen noves temptatives de Barcelona per a establir, a la ciutat, estudis de rang superior (Jutglar 1964).

SCRIPTA, Revista internacional de literatura i cultura medieval i moderna, núm. 15 / juny 2020 / pp. 241-254 ISSN: 2340-4841 · doi:/ SCRIPTA.15.17573 
La petició millor argumentada fou la que es va realitzar al juny de 1767. L'expulsió dels jesuïtes, considerats defensors de la pervivència de la Universitat, va reviscolar a Barcelona. Els regidors Francisco d'Alós, Manuel Antich, Antonio Rubalcava, el Marquès de Cartellá, el Marquès de Llió, i el Marquès de Puertonuevo, van signar una representació on assenyalaven que, a Catalunya, havien “decaigut les lletres" per la situació geogràfica de Cervera i les característiques de la seva població «impròpies per a albergar una universitat» ${ }^{10}$ (Prats 1987b).

En relació als estudis es pot afirmar que Cervera no va significar cap renovació respecte a altres universitats. Els plans d'estudi, que inicialment potenciaven una càtedra de matemàtiques i fins i tot una càtedra de filosofia cartesiana (de "Cartesio"), ${ }^{11}$ aviat es van homologar amb altres universitats amb la particularitat que les càtedres suaristes es van igualar a les tomistes. És cert que en aquest període la vàlua de determinats professors de la Companyia de Jesús, sobretot en arts, matemàtiques i filosofia, (Cerdà, Codorniu, Aymerich entre altres) la va distingir positivament en relació a altres universitats més adotzenades.

Aquest esquema va funcionar fins a l'expulsió dels Jesuïtes. A partir d'aquell moment, Cervera fou una més i no es diferencià de la resta de les principals, potser amb menys renovació de la que es podia observar a València, Granada o fins i tot a Salamanca. En l'últim terç de segle i als primers anys del xIX es detecten alguns corrents renovadors que xoquen amb el conservadorisme tradicional de la major part del professorat de la universitat. ${ }^{12}$

Es van viure les mateixes batalles entre escoles teològiques (Prats 1990) o filosòfiques; les lluites entre sectors de professors, moltes vegades per controlar les oposicions, entrant en una dinàmica endogàmica que va generar la pèrdua de prestigi si la comparem amb les potents expressions de renovació de la ciència en la segona meitat del set-cents (Prats 1989).

La Medicina es va quedar totalment al marge dels avenços de la ciència d'aquest segle. De fet, el Col legi de Cirurgia de Barcelona, creat per l'Armada, acabà constituint-se en el centre més reputat de Catalunya. Aquest va suposar una nova ruptura, aquesta vegada perfectament legal, del monopoli d'estudis que exercia Cervera. Va ser autoritzat, a més, a atorgar graus de batxiller de Filosofia, com a estudis previs a qualsevol carrera universitària. L'última dècada del segle es va convertir, a la pràctica, en l'única facultat mèdica i quirúrgica catalana. Els pocs estudiants que

10 Arxiu universitari de Cervera. Universitat de Barcelona. Caixa 77 docs. 3228,1 3228,2 y 3228,3 i caixa 1 doc. 4740 y Caja 77 doc.3261

11 Archivo de la Corona de Aragón (ACA). ESTATUTOS 1726 Títulos 32, 36, 43, 49 y 52.

12 Des de finals del segle XvIII, la Universitat de Cervera va viure una sèrie de lluites ideològiques entre dos sectors de professorat. D'una banda, els conservadors, defensors dels sabers tradicionals i de l'ordre de l'Antic Règim; estaven liderats pel cancelario Ramón Lázaro de Dou. D’altra banda, un sector de professorat jove que pugnaven per modernitzar els estudis i que, des del motí d'Aranjuez, ja van explicitar les seves posicions avançades i preliberals. Els renovadors van ser els primers a enrolar-se en la resistència antifrancesa. Al seu retorn a les aules, alguns d'aquests últims van ser apartats de la universitat. 
optaven per fer els seus estudis a Cervera, havien de cursar l'últim curs de la carrera en el Col legi de Cirurgia (Prats 1993).

L'any 1784 es va fer un pla de reforma de medicina on intervingueren el Dr. Josep Masdevall, nascut a Figueres i antic alumne de Cervera i Montpeller i metge de cambra de Carles III i Carles IV. $\mathrm{Al}$ mateix temps va assessorar el metge cerverí Jaime Bonells, membre destacat de la intel lectualitat barcelonina i gran impulsor de les societats científiques. El pla recollia bona part de les exigències més avançades de l'època, pensades per a la modernització de l'ensenyament d'aquesta facultat.. Encara que el pla es va aprovar, la medicina a Cervera mai va arribar a aconseguir un nivell acceptable, ni va poder posar-se a l'altura de les noves tendències. Un mes després d'abandonar Cervera, Josep Masdevall va enviar una carta al secretari de Gracia y Justicia:

\footnotetext{
Lo mejor sería sacar de dicha Universidad el estudio teórico de medicina y unirlo al proyectado Colegio de Medicina Práctica de Barcelona de cuyo golpe de mano resultaría con más prontitud el adelantamiento de este arte que tanto deseo. ${ }^{13}$
}

Una prova més de la incapacitat de la Universitat cerverina per aconseguir consolidar-se com a una institució prestigiosa en els sabers. En aquest cas, el govern de la Corona va confirmar, novament, que aquest centre, malgrat ser controlat directament pel Supremo Consejo de Castilla, no entrava en els plans de reforma dels estudis superiors impulsats pels sectors reformistes de la Corona.

L'anomenada «experiència cerverina» que volia ser una renovació tant dels continguts acadèmics com de la manera de funcionar, es pot considerar un relatiu fracàs, ja que la nova Universitat va acabar sent tan tradicional, acadèmicament, com qualsevol altra de les ja existents, i àdhuc amb menys elements de renovació.

El reformisme de la segona meitat del segle va oblidar a la Universitat de Cervera com a model i va intentar reformes generals, amb lleis unificadores i amb la creació d'òrgans d'intervenció progressiva a cada universitat: els directors.

Les institucions més capdavanteres de la modernització dels estudis, sobretot en ciència i tècnica, no van ser les universitats. A Catalunya varen ser l'Acadèmia de Matemàtiques, les escoles de la Junta de Comerç i l'esmentat Col legi de Cirurgia.

13 Archivo General de Simancas. Gra y Just. Ley 941, s. fol. Carta 15 Enero 1785 
El problemàtic naixement de la nova Universitat, la manca de suport institucional, l'oblit dels projectes modernitzadors del seu inici, la pressió de la ciutat de Barcelona que va reclamar sempre el retorn de la seva pròpia Universitat, la baixa qualitat dels seus professors i ensenyaments, i d' altres factors van fer que Cervera es contemplés com un projecte malmès respecte a les intencions inicials que podrien qualificar, amb algun dubte, de preilustrades.

Els il lustrats de la segona meitat del segle, Pérez Bayer, Mayans, Campomanes, Jovellanos i altres, mai la van considerar-la com un exemple pels plans de reforma que van intentar, per cert, amb molt poc èxit en el conjunt de les universitats hispanes.

\section{Bibliografia}

AA. DD. (1983) Historia de la Universidad de Zaragoza. Madrid: Editora Nacional.

Aguilar Piñal, F. (1969) La Universidad de Sevilla en el siglo XVIII. Estudios sobre la Primera reforma universitaria moderna. Sevilla: Ed. Universidad de Sevilla

Casanovas, I. (1932). Documents per la Història de Catalunya. Josep Finestres.

Clascar, F. (1918) Estudi sobre la filosofia a Catalunya el segle XVIII. Barcelona: Publicacions de La Revista Domínguez Ortiz. A. (1976) Sociedad y Estado en el siglo XVIII Español. Barcelona: Ed. Ariel, 1976

Jutglar Bernausa, A. (1964) «Notas para el estudio de la Enseñanza en Barcelona hasta 1900»en: Materiales para la historia institucional de la ciudad. Barcelona: Ayuntamiento de Barcelona.

Llaquet Entrambasaguas, J.L. (2002). La facultad de Cánones de la Universidad de Cervera. Barcelona: Ed. Atelier.

Macanaz M. (2001) Testamento de España. Instituto de Estudios Albacetenses «Don Juan Manuel» de la Excma. Diputación de Albacete (2001). Edición facsimil de un manuscrito ¿1730?)

Mora Castellà, J. (1997) La construcción a Catalunya en el segle XVIII. La Universitat de Cervera com a paradigma de l'arquitectura dels enginyers militars. S.L.: Josep Mora Castellà Ed.

Polo Rodríguez, J. L. (1994) «Reformas en la Universidad de Salamanca de los primeros Borbones (1700-1759)» A: Espacio, Tiempo y Forma, Serie IV, Ho Moderna, t. 7. 
Prats, J. (1987a) «Historiografia y publicismo sobre la Universidad de Cervera: Entre el mito y el sambenito» a : Manuscrits: revista d'història moderna, [en línia], Núm. 6, p. 49-72

\section{Decembre.}

- - (1989) «La Universidad de Cervera ante el ambiente de reformas del reinado de Carlos III. Corporativismo y tradicionalismo». En: Claustros y estudiantes. Valencia: Ed. Universidad Literaria de Valencia.

- (1990) «Iglesia, enseñanza y pensamiento en la Cataluña del Setecientos: propuestas y reflexiones». En: Esglèsia i Societat a la Catalunya del Segle XVIII. Cervera: Ed.UNED.

—_. (1993) La Universitat de Cervera i el reformisme borbònic. Lleida: Pagès Editors.

_. (1994) «El fuero académico en la Universidad de Cervera» en Fallstudien zur Justiz in modernen Spanien und Portugal volumen de la serie «Rechtsprechung. Materialien und studien. Veröffentlichungen des Max-Plank-Instituts für Europäische Rechtsgeschichte». Frankfurt am Main.

—_. (1998) «Cómo se forja un tópico historiográfico: el caso de la Universidad de Cervera» en: Palestra Universitaria. Núm. 10. UNED.

—. (2016) «Climent XII, Bula imperscrutabilis», en: AAVV. Els tresors de la Universitat de Barcelona. Barcelona: Universitat de Barcelona

Rubio Borrás, M. (1915- 1916):Historia de la Realy Pontificia Universidad de Cervera Tomo I. Barcelona: Librería Verdaguer (2 Vol.)

Soldevila, F. (1938) Barcelona sense Universitat i la restauració de la Universitat de Barcelona (1714-1837) Contribució al Centenari. Barcelona: Universitat de Barcelona.

Torras I Bages, J. (1923) La Tradició Catalana. Estudi del valor etic y racional del Regionalisme Català. Barcelona: Ed. Iberica. (1 $1^{\mathrm{a}}$ ed. 1882) 